\title{
Hand-arm vibration syndrome among travertine workers: a follow up study
}

\author{
M Bovenzi, A Franzinelli, L Scattoni, L Vannuccini
}

\section{Abstract}

In a six year follow up study of the handarm vibration syndrome, 62 stoneworkers operating hand held vibrating tools in 10 travertine quarries and mills were first investigated in 1985 and then in 1991. The frequency weighted acceleration of vibration from the rock drills and stone hammers used by the travertine workers exceeded $20 \mathrm{~m} / \mathrm{s}^{2}$, indicating a hazardous work activity according to the proposal of the EC directive for physical agents. A clinical examination and a cold provocation test were repeated with the same procedures as those adopted at the time of the first survey. The stoneworkers were divided into groups according to current work state: active stoneworkers who continued to use powered tools during the follow up ( $n=21$, median exposure time 22 years), and ex-stoneworkers with retirement vibration free intervals of three years ( $n=22$, median exposure time 27.5 years) and of six years $(n=19$, median exposure time 20 years). In the group of active stoneworkers, a $38 \%$ onset of new cases of vibration-induced white finger (VWF) was found during the follow up $(p<0.01)$. Among the retired stoneworkers affected with VWF $(n=24)$, one recovered from VWF, one showed improvement, 20 remained stationary, and two deteriorated. The exstoneworkers experienced no significant change in sensorineural disturbances and a decrease in musculoskeletal symptoms of the upper limbs. At the cold provocation test, the currently active stoneworkers with VWF showed, on a group basis, a delayed finger rewarming time between the two examinations $(p=0.002)$. An abnormal response to cold provocation persisted in the fingers of the exstoneworkers with VWF, even in those reporting subjective improvement. These findings indicate a tendency towards the irreversibility of sensorineural and VWF symptoms in a group of ex-stoneworkers with prolonged exposure to high vibration levels in the past. The increased occurrence of VWF in the active stone workers after a few extra years of vibrating tool usage argues for an urgent implementation of preventive measures in the stone industry.

(Occup Environ Med 1994;51:361-365)
Prolonged exposure to hand transmitted vibration from powered processes or tools can give rise to a complex of peripheral neurological, vascular, and musculoskeletal symptoms, called hand-arm vibration syndrome (HAVS). The vascular component of HAVS is known as vibration induced white finger (VWF), a secondary form of Raynaud's phenomenon, which is recognised as an occupational disease in most of the industrialised countries. There is some evidence for improvement or reversibility of HAVS disorders if reduction or cessation of exposure to vibration occur. Since the late 1970s, reports from Nordic countries, Great Britain, and Japan indicated a progressive decrease in the prevalence or incidence of VWF among forestry workers after the introduction of antivibration chain saws and administrative measures curtailing the saw usage time..$^{1-3}$ There is a shortage of clinical and epidemiological data on the beneficial effect of removal from vibration exposure for VWF workers who operate hand held vibrating tools other than chain saws. ${ }^{4-6}$ This paper reports the results of a six year follow up study of stoneworkers who use both percussive and rotary tools to quarry and process travertine in Tuscany (Italy). Changes in the occurrence of HAVS symptoms were investigated in active workers continuing to operate vibratory tools and retired workers three and six years after cessation of vibration exposure. A cold provocation test was also performed to assess objectively the subjective history of digital vascular disturbances.

\section{Subjects and methods}

In January and February 1985, the occurrence of HAVS was investigated in 76 stonecutters and drillers using hand held vibratory tools in 10 travertine quarries and mills. The study population represented $95 \%$ of the total work force engaged in jobs with vibrating tools in the Rapolano travertine industry (Siena, Italy). The results of this study have been reported in detail elsewhere. ${ }^{7}$ In March 1991, 62 of the previously studied stoneworkers participated in a follow up study. Of the 14 subjects lost during the six year follow up period, 12 had changed their place of residence and two had died. Among these workers, five were asymptomatic and nine complained of neurological disturbances at the time of the first examination. All the subjects affected with VWF in $1985(n=27)$ participated in the follow up. The study group underwent a clinical examination and a cold provocation test

Via della Pietà 19 Tumori,

Trieste, Italy. 
Table 1 Characteristics of the study population. Group A: active stoneworkers operating vibratory tools during the follow up period (1985-91). Group B: ex-stoneworkers with a retirement vibration free interval of three years (from 1988 to 1991). Group $C$ : ex-stoneworkers with a retirement vibration free interval of six years (from 1985 to 1991)

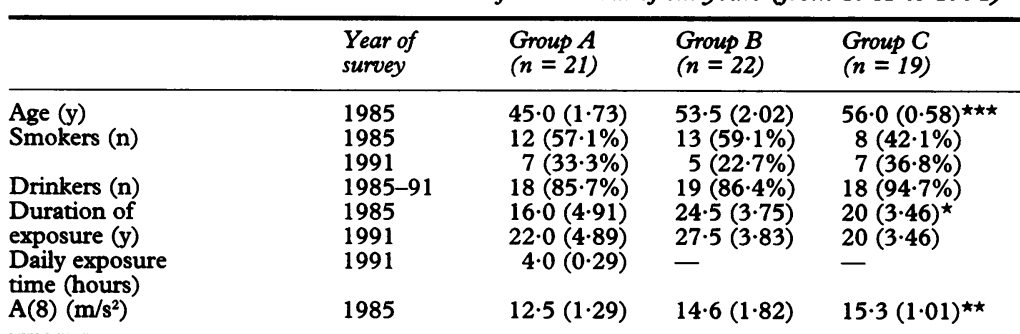

${ }^{\star} \mathrm{p}<0.05 ;{ }^{\star \star} \mathrm{p}<0.04 ;{ }^{\star \star \star} \mathrm{p}<0.001$, Kruskal-Wallis test. Values are medians (SEs of median) or numbers $(\%) ; A(8)=8$ hour frequency weighted energy equivalent acceleration.

performed by two occupational physicians who used the same procedures as those used in 1985. To study the natural course of HAVS symptoms, the subjects were divided into three groups according to current work state: group A: active stoneworkers continuing to use vibratory tools $(n=21)$; group $B$ : exstoneworkers with a retirement vibration free interval of three years, from 1988 to 1991 (n $=22)$; group C: ex-stoneworkers with a retirement vibration free interval of six years, from 1985 to $1991(n=19)$. For the subjects of groups $\mathrm{A}$ and $\mathrm{B}$, the results of a compulsory medical examination performed during the winter of 1988 were also available.

The stoneworkers were interviewed on their work history, state of health, and use of tobacco, alcohol, and medicine. Symptoms and signs of HAVS were carefully investigated during the physical examination. Symptoms of VWF were defined as cold induced episodes of blanching in one or more fingers after excluding constitutional white finger or other secondary forms of Raynaud's phenomenon. The amount of VWF was staged according to the Stockholm scale ${ }^{8}$ : stage 0 no blanching attack; stage 1 occasional attacks affecting only the tips of one or more fingers; stage 2 occasional attacks affecting distal and middle (rarely also proximal) phalanges of one or more fingers; stage 3 frequent attacks affecting all phalanges of most fingers. Current state of VWF was classified as improved, stationary, or deteriorated according to the symptom stage assessment at the end of the follow up. If no blanching attack had occurred during the past two years, the person was considered to have recovered.

The subjects were also questioned about peripheral sensorineural disturbances (tingling, numbness) and persistent pain of the neck and upper limbs. The subjective assessment of these symptoms was recorded.

Measurement of vibration was performed on the handles of the percussive and rotary tools used by the stoneworkers, according to the recommendations of the International Standard ISO $5349.9^{9}$ The mean values of frequency weighted acceleration measured in the dominant direction was $30.7 \mathrm{~m} / \mathrm{s}^{2}$ for rock drills, $24.8 \mathrm{~m} / \mathrm{s}^{2}$ for light stone hammers, and $3.12 \mathrm{~m} / \mathrm{s}^{2}$ for rotary tools (vertical grinders and hand cutters). ${ }^{7}$ Vibration exposure was assessed in terms of eight hour energy equiva- lent frequency weighted acceleration, according to the proposal of the EC directive for physical agents. ${ }^{10}$ As no changes in tool design and daily exposure time had occurred in the travertine industry during the six years between tests, the magnitude of vibration exposure for the currently active stoneworkers was estimated to have remained constant during the follow up period.

Tables 1 and 2 report the characteristics of the stoneworkers by current work state and the distribution of HAVS symptoms at the 1985 survey. At the first examination, age and vibration exposure were greater in groups B and $\mathrm{C}$ than in group $\mathrm{A}$. No difference in the distribution of HAVS symptoms was found between the various groups, with the exception of finger numbness and neck pain.

A cold provocation test was repeated under the same experimental conditions as those adopted at the time of the previous survey. After a resting period of 30 minutes in the test room at an ambient temperature of $21.0^{\circ} \mathrm{C}$, the subjects immersed their hands in cold water $\left(10^{\circ} \mathrm{C}\right)$ for five minutes while gripping a metal bar. To potentiate the ischaemic effect of cold, a blood pressure cuff, placed around the wrist, was inflated to suprasystolic level during the cooling period. Finger skin temperature was continuously measured by a thermistor probe before, during, and after the cooling period. The thermistor was placed on the tip of the same finger monitored in $\mathbf{1 9 8 5}$. The rewarming time of the fingertip was measured as the time elapsed from the end of the cooling and ischaemic period to the time when the fingertip temperature reached room temperature. ${ }^{11}$

Data analysis was by non-parametric statistics. The Mann-Whitney rank sum test and the Kruskal-Wallis one way analysis of variance were used to compare two or more independent groups. The difference between paired observations was tested by Wilcoxon's signed rank test. The McNemar test and the

Table 2 Distribution of peripheral sensorineural disturbances, vibration-induced white finger (VWF), and musculoskeletal symptoms in the neck and upper limbs of stoneworkers at the first survey in 1985. VWF is staged according to the Stockholm Workshop scale

\begin{tabular}{|c|c|c|c|}
\hline & \multicolumn{3}{|c|}{ Stoneworkers } \\
\hline & $\begin{array}{l}\text { Group } A \\
(n=21)\end{array}$ & $\begin{array}{l}\text { Group B } \\
(n=22)\end{array}$ & $\begin{array}{l}\text { Group C } \\
(n=19)\end{array}$ \\
\hline $\begin{array}{l}\text { Tingling } \\
\text { Numbness } \\
\text { VWF (stage): }\end{array}$ & $\begin{array}{l}17(81 \cdot 0) \\
11(52 \cdot 4)\end{array}$ & $\begin{array}{r}17(77 \cdot 3) \\
9(40 \cdot 9)\end{array}$ & $\begin{array}{l}13(68.4) \\
15(78.9)^{\star}\end{array}$ \\
\hline $\begin{array}{l}1 \\
2 \\
3 \\
1+2+3 \\
\text { Number of digits }\end{array}$ & $\begin{array}{l}3(14 \cdot 3) \\
1(4 \cdot 8) \\
1(4 \cdot 8) \\
5(23 \cdot 8)\end{array}$ & $\begin{array}{l}8(36 \cdot 4) \\
2(9 \cdot 1) \\
3(13 \cdot 6) \\
13(59 \cdot 1)\end{array}$ & $\begin{array}{l}3(15 \cdot 8) \\
5(26 \cdot 3) \\
1(5 \cdot 3) \\
9(47 \cdot 4)\end{array}$ \\
\hline $\begin{array}{l}\text { affected with VWF: } \\
<2 \\
3-4 \\
5-6 \\
>7 \\
\text { Musculoskeletal symptoms: }\end{array}$ & $\begin{array}{l}3(14 \cdot 3) \\
1(4 \cdot 8) \\
-1(4 \cdot 8)\end{array}$ & $\begin{array}{l}4(18 \cdot 1) \\
5(22 \cdot 7) \\
2(9 \cdot 1) \\
2(9 \cdot 1)\end{array}$ & $\begin{array}{l}- \\
3(15 \cdot 8) \\
4(21 \cdot 1) \\
2(10 \cdot 5)\end{array}$ \\
\hline $\begin{array}{l}\text { Hands } \\
\text { Wrists } \\
\text { Elbows } \\
\text { Shoulders } \\
\text { Neck }\end{array}$ & $\begin{aligned} 6(28 \cdot 6) \\
7(33 \cdot 3) \\
8(38 \cdot 1) \\
12(57 \cdot 1) \\
10(47 \cdot 6)\end{aligned}$ & $\begin{array}{l}13(59 \cdot 1) \\
11(50 \cdot 0) \\
15(68 \cdot 2) \\
13(59 \cdot 1) \\
18(81 \cdot 8)\end{array}$ & $\begin{array}{l}11(57 \cdot 9) \\
10(52 \cdot 6) \\
12(63 \cdot 6) \\
16(84 \cdot 2) \\
14(73 \cdot 7)^{\star}\end{array}$ \\
\hline
\end{tabular}

${ }^{\star} \mathrm{p}<0.05, \chi^{2}$ test. Values are numbers (\%); groups are as table 1 . 
marginal homogeneity test were used to test the equality of response rates in paired dependent data. The $\chi^{2}$ statistic was applied to data tabulated in $2 \times k$ contingency tables. Asymptotic and exact two sided $p$ values were computed with the statistical software StatXact (Cytel Software Corporation, 1992), assuming a significance limit of $0 \cdot 05$.

\section{Results}

During the follow up period, eight new cases of VWF occurred in group A (table 3). Of these, five were classified as stage 1 , two as stage 2 , and one as stage 3 . Among the stoneworkers reporting VWF in 1985, one had changed from stage 1 to stage 2, and four described their condition as stationary. In the currently active group, the prevalence of VWF was $23.8 \%$ in $1985,39.1 \%$ in 1988 , and $61.9 \%$ in $1991(p=0.013)$. At the end of the

Table 3 Change in the symptoms of the hand-arm vibration syndrome among the active stoneworkers (Group $A, n=21$ ) at the end of a six year follow up period (1985-1991)

\begin{tabular}{|c|c|c|c|c|}
\hline & \multirow{2}{*}{$\begin{array}{l}\text { Never } \\
\text { symptoms }\end{array}$} & \multicolumn{3}{|c|}{ Change in symptoms } \\
\hline & & Improving & Stationary & Deteriorating \\
\hline Tingling & 1 & 0 & 17 & 3 \\
\hline Numbness & 6 & 0 & 11 & 4 \\
\hline Stage of VWF & 8 & 0 & 4 & $9^{\star}$ \\
\hline \\
\hline & - & 0 & 4 & 9* \\
\hline \multicolumn{5}{|l|}{ Musculoskeletal symptoms: } \\
\hline Hands & 11 & 1 & 5 & 4 \\
\hline Wrists & 12 & 0 & 7 & 2 \\
\hline Elbows & 8 & 1 & 7 & 5 \\
\hline Shoulders & 6 & 1 & 11 & 3 \\
\hline Neck & 5 & 2 & 8 & 6 \\
\hline
\end{tabular}

${ }^{\star} \mathrm{p}<0.01, \mathrm{McNemar}$ test. Values are numbers of workers.

Table 4 Change in the symptoms of the hand-arm vibration syndrome at the end of the follow up among the ex-stoneworkers with a retirement vibration free interval of three years (Group B, $n=22$ )

\begin{tabular}{lcccl}
\hline & \multirow{2}{*}{$\begin{array}{l}\text { Never } \\
\text { symptoms }\end{array}$} & \multicolumn{2}{l}{ Change in symptoms } \\
\cline { 3 - 5 } & $4 m p r o v i n g$ & Stationary & Deteriorating \\
\hline Tingling & 4 & 1 & 17 & 0 \\
Numbness & 8 & 0 & 13 & 1 \\
Stage of VWF & 7 & 1 & 13 & 1 \\
Number of digits & - & 1 & 11 & 3 \\
affected with WWF & - & 4 & 8 & 0 \\
Musculoskeletal symptoms: & 10 & 5 & 6 & 0 \\
$\quad$ Hands & 11 & 7 & 8 & 2 \\
Wrists & 5 & 10 & 6 & $1^{\star}$ \\
Elbows & 5 & 10 & 7 & $1^{\star}$ \\
Shoulders & 4 & & &
\end{tabular}

${ }^{\star} \mathrm{p}<0.02 ;$ McNemar test. Values are numbers of ex-workers.

Table 5 Change in the symptoms of the hand-arm vibration syndrome at the end of the follow up among the ex-stoneworkers with a retirement vibration free interval of six years (Group $C, n=19$ )

\begin{tabular}{|c|c|c|c|c|}
\hline & \multirow{2}{*}{$\begin{array}{l}\text { Never } \\
\text { symptoms }\end{array}$} & \multicolumn{3}{|c|}{ Change in symptoms } \\
\hline & & Improving & Stationary & Deteriorating \\
\hline \multirow{10}{*}{$\begin{array}{l}\text { Tingling } \\
\text { Numbness } \\
\text { Stage of VWF } \\
\text { Number of digits } \\
\text { affected with VWF } \\
\text { Musculoskeletal symptoms: } \\
\text { Hands } \\
\text { Wrists } \\
\text { Elbows } \\
\text { Shoulders } \\
\text { Neck }\end{array}$} & 6 & 1 & 11 & 1 \\
\hline & 4 & 2 & 11 & 2 \\
\hline & 10 & 1 & 7 & 1 \\
\hline & - & 5 & 4 & 0 \\
\hline & & & & \\
\hline & 8 & 3 & 6 & 2 \\
\hline & 9 & 2 & 6 & 2 \\
\hline & 7 & 2 & 9 & 1 \\
\hline & 3 & 7 & 9 & $0^{\star}$ \\
\hline & 5 & 8 & 6 & $0^{\star}$ \\
\hline
\end{tabular}

${ }^{\star} p<0.02$, McNemar test. Values are numbers of ex-workers. follow up, the latent period for VWF (the exposure time before finger blanching) averaged 14.6 years among the affected workers. Deterioration in sensorineural and musculoskeletal symptoms was also reported by those in group $\mathrm{A}$, but the progression of these disorders was not significant.

Changes in sensorineural and VWF symptoms were negligible in groups B and C. After a vibration free interval of three years, one person in group B had recovered from VWF, one had deteriorated from stage 1 to stage 2 , and 13 had unchanged VWF symptoms (table 4). After a six year vibration free interval, one ex-stoneworker in group $\mathrm{C}$ reported a worsening of VWF symptoms, one improved from stage 3 to stage 1 , and seven remained stationary (table 5). Among these seven, however, four reported a reduction in the number of fingers affected with VWF. A fairly large proportion of ex-workers in groups $B$ and $C$ reported a decrease in musculoskeletal complaints after removal from vibration exposure, mainly with reference to neck and shoulder troubles $(p<0.02)$.

Table 6 reports the results of the cold provocation test performed at both surveys. Within each group, no difference in the rewarming time measured from the fingertip of the subjects without VWF was found between the two examinations. On a group basis, the currently active stone workers with VWF showed a significantly more prolonged rewarming time at the second than at the first cold test $(p=0.002)$. For the ex-stoneworkers with VWF in groups $B$ and $C$, no significant change in the test results was found between the two examinations. The two ex-workers reporting a decrease in VWF symptoms did not show any improvement at the finger rewarming test. In all groups, subjects with VWF exhibited a delayed rewarming with respect to those without VWF at both cold tests. The differences were significant only for groups $\mathbf{A}$ and $\mathbf{B}$.

\section{Discussion}

In the present study, a $38 \%$ onset of new VWF symptoms occurred among stonework-

Table 6 Results of the cold test performed at the first examination (1985) and at the end of the follow up (1991)

\begin{tabular}{|c|c|c|}
\hline & \multicolumn{2}{|c|}{ Rewarming time (min) } \\
\hline & First cold test & Second cold test \\
\hline $\begin{array}{l}\text { Group A: } \\
\text { Without VWF }(\mathrm{n}=8) \\
\text { With VWF }(\mathrm{n}=13) \\
\text { p Value } \\
\text { Group B: }\end{array}$ & $\begin{array}{l}1.72(0.50-5 \cdot 50) \\
3.00(1 \cdot 72-15 \cdot 0) \\
0.03\end{array}$ & $\begin{array}{l}1.68(0.72-3.92) \\
5.18(1.83-15.0)^{\star} \\
0.002\end{array}$ \\
\hline $\begin{array}{l}\text { Without VWF }(n=7) \\
\text { With VWF }(n=15) \\
\text { p Value }\end{array}$ & $\begin{array}{l}1.67(1 \cdot 17-2 \cdot 25) \\
9 \cdot 00(1 \cdot 42-14 \cdot 0) \\
0.003\end{array}$ & $\begin{array}{l}1 \cdot 72(1 \cdot 17-3 \cdot 78) \\
8.67(0 \cdot 50-15 \cdot 0) \\
0.003\end{array}$ \\
\hline $\begin{array}{l}\text { Group C: } \\
\text { Without VWF }(n=10) \\
\text { With VWF }(n=9) \\
\text { p Value }\end{array}$ & $\begin{array}{l}2.08(1.00-11.4) \\
3.17(1.17-15.0) \\
0.38\end{array}$ & $\begin{array}{l}2 \cdot 75(1 \cdot 08-11 \cdot 7) \\
3 \cdot 33(1 \cdot 18-15 \cdot 0) \\
0 \cdot 15\end{array}$ \\
\hline
\end{tabular}


ers who continued operating hand held vibrating tools during a six year follow up period. In this group of active stoneworkers, the prevalence of VWF was about $62 \%$ at the end of the follow up. The increased reaction of fingers to hand cooling and ischaemia confirmed objectively the impairment to digital circulation in the subjects who either developed VWF during the follow up or complained of deterioration in their vascular symptoms. These findings are consistent with the results of other epidemiological studies of stonecutters and drillers, in which VWF prevalences of $29-89 \%$ have been reported. ${ }^{12-16}$ The increased occurrence of VWF in the stone industry is likely to be the result of a summation of several risk factors including exposure to high acceleration magnitudes from powered tools, excessive duration of exposure, and exposure to external cold climate or to a cold and humid indoor environment.

In this study, we found neither significant reversibility nor progression of sensorineural and VWF symptoms in two groups of exstoneworkers with vibration free intervals of three and six years. Most of those affected with VWF (83.3\%) reported stationary symptoms. The spontaneous recovery or improvement reported by two ex-stoneworkers was counterbalanced by VWF deterioration in two others. Even though six ex-stoneworkers reported a reduction in the number of affected digits, this finding was associated with improvement in VWF stage in only two exworkers. The reversibility of HAVS symptoms on removal from exposure to vibration is still a controversial matter. For some occupational groups (for example, chain saw operators) there is epidemiological evidence for recovery from VWF after discontinuing exposure or use of antivibration chain saws. In an 11 year prospective study, Riddle and Taylor ${ }^{1}$ reported a fall in VWF prevalence from $65 \%$ to $30 \%$ in a group of $\mathbf{4 3}$ forestry workers who had stopped using chain saws. Among the ex-saw operators affected with VWF, however, four men complained of deterioration in VWF symptoms. Further evidence for improvement or reversal of VWF on cessation of exposure to vibration came from a cohort study of 429 VWF ex-chain saw operators followed up by Futatsuka et $a l^{2}$, who reported a $42.5 \%$ recovery rate over a 20 year period. Nevertheless, the reversibility of VWF depended on the original severity of the disease, as at the end of the follow up the prevalence of VWF was $8.3 \%$ in patients at stage 1 (Stockholm scale) and $91.5 \%$ in patients at stage $3 .^{2}$ A gradual decrease in VWF prevalence from $40 \%$ in 1972 to $5 \%$ in 1990 has been found in Finnish lumberjacks, mainly as a result of the introduction of lighter antivibration chain saws in forest work. ${ }^{3}$ There are few studies on VWF reversibility among occupational groups exposed to vibration from powered tools other than chain saws. Furthermore, the results of these studies seem to be contrasting. Following up a population of ex-users of rotary polishing tools,
Agate $^{4}$ in 1949 reported unchanged VWF symptoms in $50 \%$ and deterioration in $36 \%$ of the subjects after a two and a half year period. In the early $1950 \mathrm{~s}$, Jepson ${ }^{5}$ confirmed that VWF, once established, tended to persist even though exposure to vibration had ceased. By contrast, in 1970 Stewart and Goda ${ }^{6}$ and later in $1982 \mathrm{Hursh}^{17}$ reported improvement of VWF in respectively $27 \%$ and $78 \%$ of exusers of hand held vibratory tools employed in a great variety of industrial operations including drilling, hammering, and grinding. In a more recent follow up study of riveters in the aircraft industry, Dandanell $e t a l^{18}$ found no significant decrease in VWF among subjects unexposed from 1984 to 1990 . The natural course of VWF in a group of retired stonecutters and carvers has been reported by Taylor et $a^{16}{ }^{16}$, who in 1978 revisited the limestone quarries of Bedford (Indiana, USA), originally investigated by Alice Hamilton in $1918 .{ }^{12}$ In a group of eight ex-stonecutters with a mean vibration exposure time of 45 years and a mean retirement period of 6.6 years, there were five VWF stage 2 (Taylor-Pelmear scale), two stage 3, and one stage 0 . These findings seem to be consistent with the results of the present follow up study, suggesting a tendency towards the irreversibility of VWF in groups of affected ex-stoneworkers with prolonged exposure to high vibration levels in the past. It should be noted that quarry drilling and stone cutting involve the use of vibrating tools that can transmit to the hand and arm system acceleration magnitudes greater than $20 \mathrm{~m} / \mathrm{s}^{2}$, indicating a hazardous work activity according to the proposal of the EC directive for physical agents. ${ }^{10}$ The presence of age related arteriosclerotic obstructions in the supplying arteries of the fingers may provide a further explanation for the persistence of VWF in the retired stoneworkers who were, on average, in their $60 \mathrm{~s}$. That the reversibility of VWF is inversely associated with age has been suggested by Futatsuka et al, ${ }^{19}$ who noted less improvement in those with VWF who were aged over 50 than in younger VWF groups.

In our study, an abnormal response to cold provocation was found to persist in the exstoneworkers with VWF, even in those reporting subjective improvement. This finding is similar to that reported by Ekenvall and Carlsson, ${ }^{20}$ who found no significant change in the impairment to cold reaction of digital arteries in patients with a history of subjective improvement or stationary symptoms during a 3.5-6 year follow up period.

With regard to the other components of HAVS, the ex-stoneworkers of this study experienced no significant variation in sensorineural disturbances and a decrease in neck and arm pain. Some longitudinal studies have shown that numbness of the hands and arms is more resistant to improvement or recovery than vascular disorders. ${ }^{23}$ This finding was also confirmed objectively by Taylor et $a,^{16}$ who found sensory abnormalities at the clinical tests in all but one of the retired stonecutters examined in the Bedford area. The 
reduction in physical strain due to withdrawing from hard manual work and vibration exposure is likely to be the main reason for the subjective improvement in musculoskeletal complaints reported by the ex-stoneworkers of this investigation. This is consistent with the decreased occurrence of arm pain found by Stewart and $\mathrm{Goda}^{6}$ in their retrospective study of ex-users of vibrating tools.

In conclusion, this follow up study pointed out a severe progression of VWF symptoms in stoneworkers who continued to use vibratory tools and no abatement in the prevalence of sensorineural and vascular disorders among retired stoneworkers. That a few extra years of vibrating tool usage have caused a significant increase in the occurrence of VWF among the active stoneworkers is a matter of concern and argues for an urgent implementation of preventive measures in the stone industry. It is possible that a follow up of three to six years is too short to show changes in HAVS symptoms among the ex-stoneworkers. Nevertheless, the work history of these men and their age distribution, as well as the results of a previous follow up study of retired stonecutters, ${ }^{16}$ seem to indicate that sensorineural disturbances and VWF symptoms will improve very slowly, if at all, in the affected subjects.

1 Riddle HFV, Taylor $W$. Vibration-induced white finger among chain sawyers nine years after the introduction of anti-vibration measures. In: Brammer AJ, Taylor W, anti-vibration measures. In: Brammer AJ, Taylor W, eds. Vibration effects on the hands and arm in

2 Futatsuka M, Ueno T, Kitano T, et al. Cohort study of the sequence of vibration syndrome due to chain saw operation. In: Okada A, Taylor W, Dupuis H, eds. Hand-Arm vibration. Kanasawa: Kyoei Press Co, 1989:117-20.

3 Koskimies K, Pyykkö I, Starck J, Inaba R. Vibration syndrome among Finnish forest workers between 1972 and 1990. Int Arch Occup Environ Health 1992;64:251-6.
4 Agate IN. An outbreak of cases of Raynaud's phenomenon of occupational origin. Br f Ind Med 1949;6:144-63.

5 Jepson RP. Raynaud's phenomenon in workers with vibratory tools. Br f Ind Med 1954;11:180-5

6 Stewart AM, Goda DF. Vibration syndrome. Br f Ind Med 1970;27:19-27.

7 Bovenzi M, Franzinelli A, Strambi F. Prevalence of vibration-induced white finger and assessment of vibration exposure among travertine workers in Italy. Int Arch Occup Environ Health 1988;61:25-34.

8 Gemne G, Pyykkö I, Taylor W, Pelmear PL. The Stockholm Workshop scale for the classification of cold-induced Raynaud's phenomenon in the handarm vibration syndrome (revision of the Taylor-Pelmear scale). Scand $\mathcal{F}$ Work Environ Health 1987;13:275-8.

9 International Organization for Standardization. Mechanical vibration-guidelines for the measurement and the assessment of human exposure to hand-transmitted vibration. Geneva, ISO 5349:1986.

10 Council of the European Communities. Proposal for a Council Directive on the minimum health and safety requirements regarding the exposure of workers to the risks arising from physical agents. Official Journal of the European Communities, 93/C77/02, No C 77/12-29, 18.3.93.

11 Juul C, Nielsen SL. Locally induced digital vasospasm detected by delayed rewarming in Raynaud's phenomedetected by delayed rewarming in Raynaud's phenome-

non of occupational origin. $B r f$ Ind Med 1981;38:87-90.
12 Hamilton A. A study of spastic anemia in the hands of stonecutters. In: Bull US Bureau of Labor Statistics No 236: Industrial accidents and hygiene series No 191. Washington DC: Government Printing Office, 1918 53-66.

13 Miura T. On the vibration syndrome in Japan due to handheld vibration tools. Fournal of Science of Labour 1975;31:771-87.

14 Färkillä M, Starck J, Hyvarinen J, Kurppa K. Vasospastic symptoms caused by asymmetrical vibration exposure of the upper extremities to a pneumatic hammer. Scand $\mathcal{f}$ Work Environ Health 1978;4:330-5.

15 Olsen N, Nielsen SL. Diagnosis of Raynaud's phenomenon in quarrymen's traumatic vasospastic disease. Scand non in quarrymen's traumatic vasospastic

16 Taylor W, Wasserman D, Behrens V, Reynolds D, Samueloff S. Effect of the air hammer on the hands of stonecutters. The limestone quarries of Bedford, Indiana, revisited. Br f Ind Med 1984;41:289-95.

17 Hursh HJ. Vibration-induced white finger-reversible or not. A preliminary report. In: Brammer AJ, Taylor W, eds. Vibration effects on the hand and arm in industry. New York: John Wiley and Sons, 1982:193-5.

18 Dandanell R, Engström K, Magnusson L, Ottersten S. Exposure conditions and Raynaud's phenomenon among riveters in the aircraft industry - a follow up among riveters in the aircraft industry-a follow up study. In: Proceedings of the 6th International

19 Futatsuka M, Ueno T, Sakurai T. Follow up study of vibration induced white finger in chain saw operators. $\mathrm{Br}$ f Ind Med 1985;42:267-71.

20 Ekenvall L, Carlsson A. Vibration white finger: a follow up study. Br $\mathcal{F}$ Ind Med 1987;44:476-8. 